\title{
The Psychosocial Impact of Self-Reported Morning Allergy Symptoms: Findings from an Australian Internet-Based Survey
}

\author{
Timothy J. Sharp ${ }^{1,2}$ and Celina Seeto ${ }^{3,4}$ \\ ${ }^{1}$ RMIT School of Health Sciences, Melbourne, VIC 3083, Australia \\ ${ }^{2}$ Happiness Institute, Suites 101/102, 74 Pitt Street, Sydney NSW 2000, Australia \\ ${ }^{3}$ Faculty of Pharmacy, Building A15, The University of Sydney, Sydney NSW 2006, Australia \\ ${ }^{4}$ Schering-Plough Pty Limited, Level 4, 66 Waterloo Road, North Ryde NSW 2113, Australia \\ Correspondence should be addressed to Timothy J. Sharp, tim@thehappinessinstitute.com
}

Received 23 December 2009; Revised 1 April 2010; Accepted 5 April 2010

Academic Editor: William E. Berger

Copyright ( $\odot 2010$ T. J. Sharp and C. Seeto. This is an open access article distributed under the Creative Commons Attribution License, which permits unrestricted use, distribution, and reproduction in any medium, provided the original work is properly cited.

\begin{abstract}
Background. Allergies can substantially impact health-related quality of life (HRQL). We investigated the psychosocial impact of morning symptoms amongst Australian adults with self-reported allergic rhinitis (AR). Method. An online survey comprising 24 questions was conducted in August 2008. Inclusion criteria were age (20-49 years) and self-reported moderate to severe symptoms of AR. Results. One thousand sixty respondents met the inclusion criteria. Amongst consumers with self-reported AR, symptoms were more severe in the morning in 597 (56\%) and affected mood in 1025 (97\%). Nine hundred seventy (91\%) indicated that their symptoms had some impact on their day ahead and 868 (82\%) reported a negative impact on relationships. Morning symptoms in particular had a substantial affect on mood for the day. HRQL impact was more pronounced in those who reported severe symptoms and in females. Discussion. Encouraging consumers with self-diagnosed AR to seek formal diagnosis and offering appropriate treatment strategies, such as those offering sustained effectiveness over 24-hours, may aid in negating the negative impact of morning symptoms.
\end{abstract}

\section{Introduction}

Currently one in five (4.1 million) Australians have at least one allergy; with prevalence estimated to be growing at a rate of $0.09 \%$ per annum [1]. Most suffer from more than one condition at a time (an average of 1.74 comorbid allergies per person) and over half (51.4\%) are 20-49 years of age [1].

The prevalence of allergic rhinitis is increasing; approximately $16 \%$ of Australians have allergic rhinitis, including about $19 \%$ of working aged adults [2]. The relative risk of mortality due to allergic rhinitis is low [1]; explaining why it has previously been regarded as a trivial condition. However, it is widely accepted that allergic rhinitis can have a significant negative impact on several areas of healthrelated quality of life (HRQL) [3-5]. Daily activities are impaired in more than $80 \%$ of patients with moderate or severe allergic rhinitis and $40 \%$ of those with mild disease
[6]. Health impairment often leads to work impairment in the form of both absenteeism and presenteeism. The ability of allergic rhinitis sufferers to engage in productive work has been shown to be influenced by sleep, HRQL, specific symptoms, and antihistamine use [7]. Our survey examined the impact of self-reported allergic rhinitis on the emotional and psychological wellbeing of Australian adults.

\section{Methods}

In August 2008, an online survey was conducted amongst participants from a permission based panel (Galaxy DP Pty Ltd, Australia). In a permission based panel, all panellists give prior permission to receive email invitations to participate in research. With each invitation they have the opportunity to accept or decline and are paid $\$ 2.00$ to participate in each survey. A minimum sample size of 200 participants per state was sought to ensure a representative sample. 
The total sample was then weighted to national population proportions (issued by the Australian Bureau of Statistics (ABS) ) based on state, age, and gender.

The survey tool was not validated, but was based on that previously used by Long in a similarly conducted research carried out in the US in 2005 [8]. The survey comprised five screening questions, six demographic questions and 13 questions relating to the respondents' self-reported experience of allergies and their subsequent impact on quality of life. The questionnaire was administered in English only. No identifying data were collected.

Male and female respondents, aged 20 to 49 years, were included if they had self-reported moderate to severe hay fever, hives/skin allergies, or allergies triggered by airborne factors (pet dander, pollen/grass, dust mites, mould). In addition, patients were asked to report "How often they suffer from allergies?" The possible options for this question were based on the ARIA guideline classification of intermittent versus persistent allergic rhinitis [9]. The options listed corresponded to the classification as such: intermittent allergic rhinitis = less than four days a week and seasonally for less than four weeks at a time and persistent allergic rhinitis = more than four days a week and seasonally for more than four weeks at a time.

Respondents were excluded if they had self-reported mild allergies, only asthma, or had allergies triggered by any factors other than those listed above.

Participants' responses were summarised and analysed to identify any significant differences between groups. Statistical analysis was conducted using $z$ tests for the difference between proportions.

\section{Results}

3.1. Respondent Characteristics. One thousand, four hundred fifty three people responded to the survey, of whom 1060 met the study criteria, completed the survey and were included in the study results. Overall demographic characteristics are listed in Table 1.

Of the respondents who met the study criteria, $82 \%(n=865)$ self-reported having "moderate" symptoms and $18 \%(n=195)$ self-reported having "severe" symptoms. The most frequently self-reported type of allergy was hayfever $(n=879)$, followed by pollen/grass allergies $(n=$ $665)$, hives/skin allergies $(n=450)$, dust mite allergies $(n=$ $420)$, pet allergies $(n=399)$, and mould allergies $(n=199)$.

3.2. Relationship of Self-Reporting with ARIA Classification. Of the respondents who self-reported as having "moderate" symptoms, 55\% ( $n=479 / 865)$ stated having allergy symptoms that would be classified as being persistent allergic rhinitis sufferers. Whereas, $76 \%(n=148 / 195)$ of those who reported having "severe" allergy symptoms would be classified as being persistent allergic rhinitis sufferers.

3.3. Assessment of Allergy Symptoms. Of the respondents who reported having moderate symptoms, 54\% ( $n=466 / 865)$ reported that they "always or mostly" used medication to
TABLE 1: Demographic characteristics of respondents with selfreported allergic rhinitis $(N=1060)^{*}$.

\begin{tabular}{|c|c|}
\hline Characteristic & Number $(\%)$ \\
\hline \multicolumn{2}{|l|}{ Gender } \\
\hline Male & $515(49)$ \\
\hline Female & $545(51)$ \\
\hline \multicolumn{2}{|l|}{ Age (years) } \\
\hline 20-29 & $381(36)$ \\
\hline $30-39$ & $355(33)$ \\
\hline $40-49$ & $325(31)$ \\
\hline \multicolumn{2}{|l|}{ Geographical location } \\
\hline $\begin{array}{l}\text { New South Wales/Australian } \\
\text { Capital Territory }\end{array}$ & $371(35)$ \\
\hline Victoria/Tasmania & $293(28)$ \\
\hline Queensland & $210(20)$ \\
\hline South Australia & $79(7)$ \\
\hline Western Australia & $107(10)$ \\
\hline \multicolumn{2}{|l|}{ Marital status } \\
\hline Married & $460(43)$ \\
\hline De facto/Living together & $244(23)$ \\
\hline Separated, widowed, or divorced & $76(7)$ \\
\hline Never married & $280(26)$ \\
\hline \multicolumn{2}{|l|}{ Children } \\
\hline Yes & $570(54)$ \\
\hline No & $490(46)$ \\
\hline \multicolumn{2}{|l|}{ Work status } \\
\hline Full time & $657(62)$ \\
\hline Part time & $176(17)$ \\
\hline Full time student & $78(7)$ \\
\hline Not working/studying & $150(14)$ \\
\hline $\begin{array}{l}\text { *Weighted sample. The sample was weig } \\
\text { of Statistics estimates based on state, age } \\
\text { of respondents from each state was } 215 \text { ( } \\
\text { (QLD); } 206 \text { (SA); } 200 \text { (WA). }\end{array}$ & $\begin{array}{l}\text { e actralian Bureau } \\
\text { (VIC/TAS); } 220\end{array}$ \\
\hline
\end{tabular}

treat their allergy symptoms, whilst 46\% $(n=399 / 865)$ reported that they "sometimes" used medications to treat their allergy symptoms. This is in contrast to those who reported having severe symptoms, where $82 \%(n=159 / 195)$ reported that they "always/mostly" used medication and $19 \%(n=36 / 195)$ reported that they "sometimes" used medication.

Over half of all the participants $(597 ; 56 \%)$ reported that their allergy symptoms were more severe in the morning than at any other time of the day (Figure 1). There was no discernable difference between those who reported having "moderate" $(55 \%, n=477 / 875)$ or "severe" $(62 \%, n=$ $120 / 185$ ) symptoms. More females reported that their allergy symptoms were at their worst in the mornings (Females: $60 \%$ [328/545] versus Males: 52\% [269/515]; $P<.01)$.

When asked which symptoms were worse in the morning, sneezing $(630 ; 59 \%)$, itchy/watery eyes $(621 ; 59 \%)$, running nose $(542 ; 51 \%)$, and blocked nose $(459,43 \%)$ were the most frequently reported. "Runny nose" (630; 63\%) and 
"blowing nose" (610; 58\%) were the most frequently reported symptoms which made respondents feel embarrassed or unattractive around others.

3.4. Assessment of Psychosocial Impact. The majority of respondents reported that their symptoms had an impact on their lives, either by waking them up $(88 \% ; n=$ 931/1060) or by affecting their mood for the day (97\%; $n=1025 / 1060)$. When asked how their symptoms affected their mood for the day (Table 2), being "irritable" and being "tired and exhausted" were most commonly reported. Almost all respondents $(970 ; 91 \%)$ indicated that their symptoms had some impact on their day ahead, 868 (82\%) reporting a negative impact on relationships and/or family life, and 969 (91\%) reporting that their symptoms had prevented them from doing something they would usually have done (e.g., exercised or gone to work).

With the exception of reporting being "tired and exhausted," those with self-reported severe allergy symptoms had a significantly higher impact on their mood compared to those with self-reported moderate allergy symptoms $(P<$ $.05)$. Significantly more females than males expressed that their symptoms made them "irritable," "tired and exhausted", and "depressed" ( $P<.05$ for each measure; Table 2$)$. A similar trend was seen with responses to the impact on the day ahead (Table 2). Females reported a significantly higher impact than males for several measures relating to appearance and or interpersonal interactions. In contrast, males were significantly more likely to report that their professionalism at work would be compromised (24\% [125/515] versus $17 \%$ [93/545], $P<.05)$.

The impact of morning symptoms on mood was analysed by the time of day that the symptoms were most severe (Figure 2). Respondents who reported that their symptoms were most severe during the morning were more likely to report that their condition made them "grumpy," "moody," and "frustrated." Conversely, people who suffered more at other times of the day (including the night time) were more likely to report feeling "irritable" and "tired and exhausted." The negative impact of morning allergy symptoms also extended to how people behaved during the day (Figure 3), with a significant impact on usual morning behavioural patterns ("dreading public transport," "feeling the need to explain that you are not sick", and "being less affectionate with partner and children").

\section{Discussion}

Much work has already been conducted to determine the impact of allergic rhinitis on HRQL, however, most is focussed on individuals with verified allergy leaving out those with self-reported allergy symptoms. Our study has shown that self-reported symptoms of moderate to severe allergic rhinitis have a significant negative impact on emotional and psychological wellbeing. Almost two out of every three respondents reported being either "irritated" or "tired and exhausted" as a consequence of their symptoms. Morning symptoms, in particular, have a substantial impact on mood for the day (sufferers report feeling more "grumpy,"

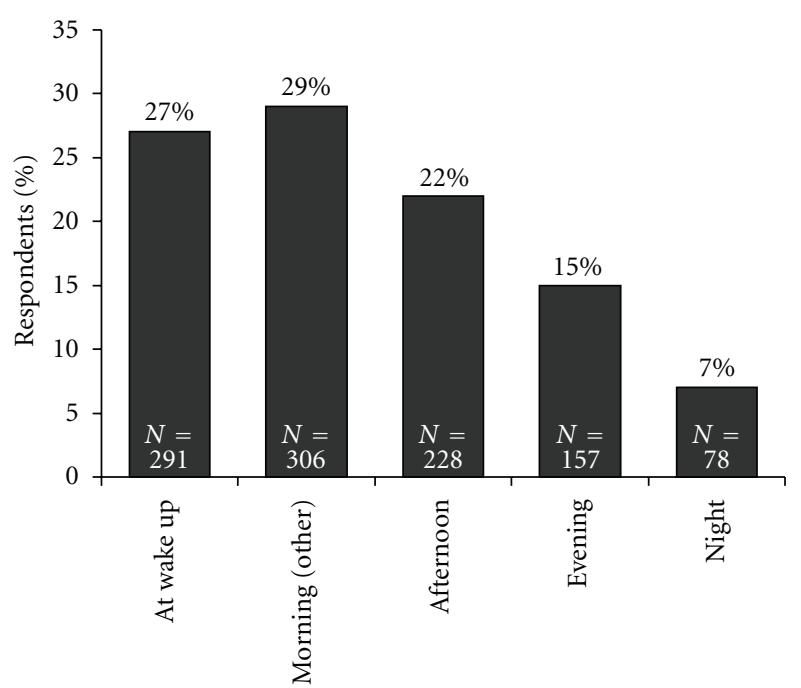

Figure 1: Time when allergy symptoms are most severe. Percentage of respondents who replied to the question "When are your allergy symptoms most severe?"

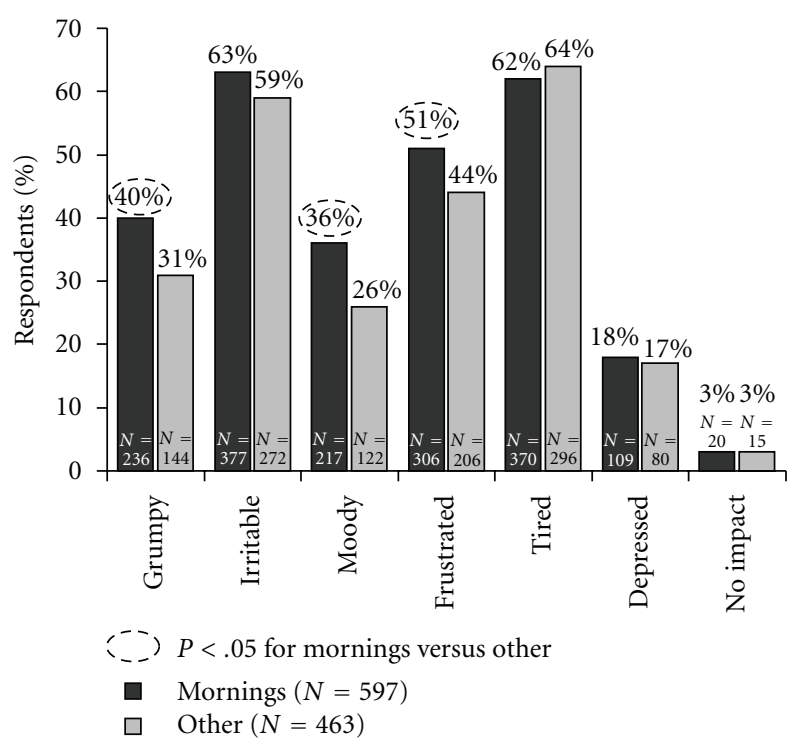

FIGURE 2: Impact of morning allergy symptoms on mood for the day. Percentage of respondents who replied to the question "When you get allergies, how does it affect your mood for the day?"

"moody," and "frustrated") as well as on their usual daily activities. These findings are similar to those published previously, which demonstrated that morning allergy symptoms not only have a negative impact on the quality of life of individuals with moderate to severe allergic rhinitis but that that these symptoms substantially impact the person for the rest of the day [8]. The results obtained in our study have extended these findings, demonstrating how symptoms in people who report self-awareness of allergic rhinitis negatively impact on home and work life and relationships with partners. 
TABLE 2: Impact of self-reported allergies on mood for the day and the day ahead.

\begin{tabular}{|c|c|c|c|c|c|}
\hline \multirow[b]{2}{*}{ Characteristic } & \multirow{2}{*}{ All respondents $N(\%)$} & \multicolumn{2}{|c|}{ Gender $N(\%)$} & \multicolumn{2}{|c|}{ Symptom severity $N(\%)$} \\
\hline & & Male & Female & Severe & Moderate \\
\hline \multicolumn{6}{|c|}{ "When you get allergies, how does it affect your mood for the day?" } \\
\hline Grumpy & $380(36)$ & $184(36)$ & $196(36)$ & $99(51)^{\ddagger}$ & $281(32)$ \\
\hline Irritable & $650(61)$ & $301(58)$ & $349(64)^{*}$ & $129(66)^{\ddagger}$ & $521(60)$ \\
\hline Moody & $340(32)$ & $174(34)$ & $166(30)$ & $87(44)^{\ddagger}$ & $253(29)$ \\
\hline Frustrated & $511(48)$ & $237(46)$ & $274(50)$ & $106(54)^{\ddagger}$ & $406(47)$ \\
\hline Tired and exhausted & $666(63)$ & $305(59)$ & $361(66)^{*}$ & $128(66)$ & $537(62)$ \\
\hline Depressed & $188(18)$ & $81(16)$ & $107(20)^{*}$ & $53(27)^{\ddagger}$ & $135(16)$ \\
\hline No impact & $35(3)$ & $18(3)$ & $17(3)$ & $10(5)$ & $26(3)$ \\
\hline \multicolumn{6}{|c|}{ "What impact do your allergies have on your day ahead?" } \\
\hline Reluctant to go to work & $426(40)$ & $221(43)$ & $205(38)^{*}$ & $80(41)$ & $346(40)$ \\
\hline $\begin{array}{l}\text { Less affectionate with partner or } \\
\text { children }\end{array}$ & $405(38)$ & $197(38)$ & $208(38)$ & $101(52)^{\ddagger}$ & $304(35)$ \\
\hline Avoid people/public places & $335(32)$ & $142(28)$ & $193(35)^{*}$ & $76(39)^{\ddagger}$ & $259(30)$ \\
\hline Embarrassed about appearance & $329(31)$ & $140(27)$ & $190(35)^{*}$ & $68(35)$ & $262(30)$ \\
\hline $\begin{array}{l}\text { Unable to participate in everyday } \\
\text { activities }\end{array}$ & $380(36)$ & $191(37)$ & $189(35)$ & $82(42)^{\ddagger}$ & $298(34)$ \\
\hline $\begin{array}{l}\text { Need to explain that you are not } \\
\text { sick }\end{array}$ & $400(38)$ & $168(33)$ & $232(43)^{*}$ & $87(45)^{\ddagger}$ & $313(36)$ \\
\hline Dread taking public transport & $160(15)$ & $72(14)$ & $87(16)$ & $33(17)$ & $127(15)$ \\
\hline Feel sorry for yourself & $398(38)$ & $158(31)$ & $240(44)^{*}$ & $89(46)^{\ddagger}$ & $309(36)$ \\
\hline $\begin{array}{l}\text { Professionalism will be } \\
\text { compromised }\end{array}$ & $219(21)$ & $125(24)^{\dagger}$ & $93(17)$ & $52(26)^{\ddagger}$ & $167(19)$ \\
\hline People will avoid you & $168(16)$ & $74(14)$ & $94(17)$ & $39(20)^{\ddagger}$ & $129(15)$ \\
\hline None of the above & $90(9)$ & $50(10)$ & $40(7)$ & $13(7)$ & $77(9)$ \\
\hline
\end{tabular}

${ }^{*} P<.05$ for females versus males; ${ }^{\dagger} P<.05$ for males versus females; ${ }^{\ddagger} P<.05$ for people with severe versus moderate symptoms.

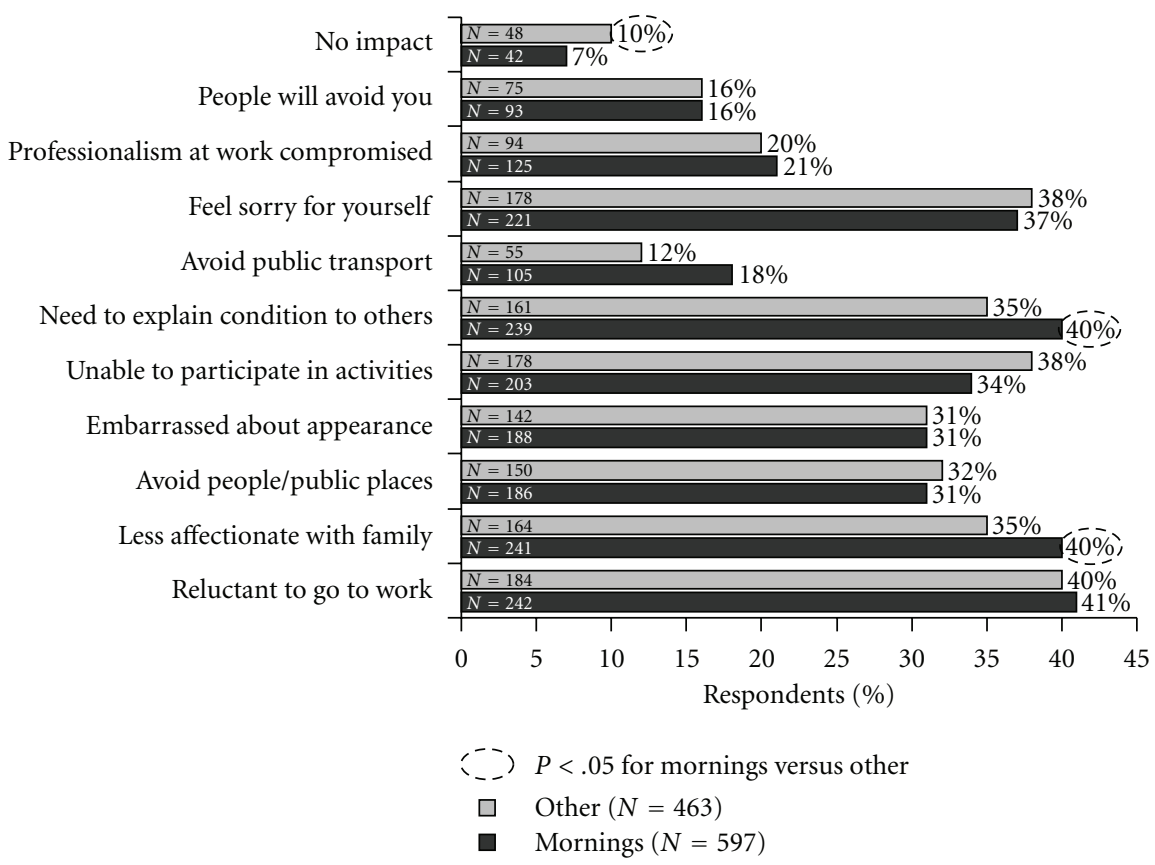

FIGURE 3: Impact of morning allergy symptoms on the day ahead. Percentage of respondents who replied to the question "What impact do your allergies have on your day ahead?" 
Both seasonal and perennial allergic rhinitis sufferers may develop a group of psychological complaints related to symptom severity [10]. Perceptions of symptom severity have been shown to be positively associated with personality factors (hypochondriasis and somatic awareness) whilst being independent of skin prick test results [11]. Neuroticism, the tendency to experience negative emotions and to be highly self-conscious and somatically concerned, has been positively correlated with allergy [12]. Furthermore, findings suggest that less adaptive coping strategies are associated with higher levels of psychological distress amongst allergy sufferers [13].

Gender differences were apparent in our study, particularly in areas of the questionnaire related to appearance. This could be explained by sociocultural attitudes, females have a greater willingness to acknowledge and report symptoms. Gender-specific differences in the interpretation of symptoms and their impact on the individual have previously been reported $[14,15]$. Moreover, gender is known to play a strong role in depression and other psychological disorders. Amongst a sample of self-reported adult allergy sufferers in the US, there was a significant relationship between allergy and depression in women but not in men [12]. In the attempt to better understand the links between allergy and psychological status it is still not clear which comes first.

The most notable limitation of our study is that the questionnaire used was not formally validated. The questions were developed based on review of prior published instruments and conformed closely to that utilised by Long [8]. Our questionnaire extended focused predominantly on the emotional and psychological impact of typical allergic rhinitis symptoms. As such, our questionnaire had an increased focus on how the symptoms made the respondent feel and which particular symptoms made them feel embarrassed or unattractive while at work or in the presence of others. The absence of a numerical response scale in the questionnaire limits the ability to compare our results with those obtained in other studies. Although the sample sizes were weighted with respect to ABS data, a permission-based panel was used such that the study population may not be representative of the general allergy population.

Nasal congestion has been described as " $a$ cardinal symptom of allergic rhinitis" [16]. In our study only $43 \%$ of respondents reported that nasal congestion was worse in the morning, which is lower than was expected. One explanation for this discrepancy is that it is a direct result of a problem with the data collection tool. The question asked was "For you, which allergy symptoms are worse in the mornings?" It may be that nasal congestion is always present and therefore does not get worse in the mornings. Alternatively, our result may simply reflect that the study respondents did not have to have a prior physician diagnosis of allergy. This is consistent with prior research; it has previously been shown that nasal congestion is the symptom most likely to prompt a person with allergic rhinitis to seek medical help [17] and that "blocked nose" is not the dominant symptom in people who self-report awareness of allergic rhinitis [18].
The widespread availability of nonprescription allergy medications means that many people with symptoms suggestive of allergic rhinitis self-diagnose their condition and present to the pharmacy for treatment. In many cases they are then able to self-select a medication without recourse to health professional advice. It has previously been established that self-management of allergy symptoms is enhanced when healthcare professional intervention is sought and tailored goals established [19]. We have shown that symptoms, particularly those that are most severe in the mornings, can substantially impact the overall emotional and psychological wellbeing of consumers who are self-aware of allergic rhinitis and who are self-medicating. Encouraging these consumers to seek formal diagnosis and then combining appropriate treatment strategies, such as those offering sustained effectiveness over 24-hours, with an individually tailored, goal-oriented, and self-management program may aid in optimising symptom management.

\section{Acknowledgments}

This study was funded by Schering-Plough Pty Ltd, Australia. The authors would like to thank Hazel Palmer of Scius Solutions Pty Ltd, Sydney, Australia for assistance in the preparation of this manuscript; Ms. Palmer's contribution has been funded by Schering-Plough Pty Ltd, Australia.

\section{References}

[1] Access Economics, "Australasian Society of Clinical Immunology and Allergy. The economic impact of allergic disease in Australia: not to be sneezed," 2007, http://www.accesseco_ nomics.com.au/publicationsreports/getreport.php?report 158 \&id $=205$.

[2] Australian Institute of Health and Welfare, Australia's Health 2006, AIHW, Canberra, Australia, 2006.

[3] R. A. Nathan, "The burden of allergic rhinitis," Allergy and Asthma Proceedings, vol. 28, no. 1, pp. 3-9, 2007.

[4] I. C. Camelo-Nunes and D. Solé, "Allergic rhinitis: indicators of quality of life," Jornal Brasileiro de Pneumologia, vol. 36, no. 1, pp. 124-133, 2010.

[5] E. O. Meltzer, R. Nathan, J. Derebery, et al., "Sleep, quality of life, and productivity impact of nasal symptoms in the United States: findings from the Burden of Rhinitis in America survey," Allergy and Asthma Proceedings, vol. 30, no. 3, pp. 244-254, 2009.

[6] J. Bousquet, F. Neukirch, P. J. Bousquet, et al., "Severity and impairment of allergic rhinitis in patients consulting in primary care," Journal of Allergy and Clinical Immunology, vol. 117, no. 1, pp. 158-162, 2006.

[7] S. L. Szeinbach, E. C. Seoane-Vazquez, A. Beyer, and P. B. Williams, "The impact of allergic rhinitis on work productivity," Primary Care Respiratory Journal, vol. 16, no. 2, pp. 98$105,2007$.

[8] A. A. Long, "Findings from a 1000-patient internet-based survey assessing the impact of morning symptoms on individuals with allergic rhinitis," Clinical Therapeutics, vol. 29, no. 2, pp. 342-351, 2007.

[9] ARIA, "ARIA: at a glance pocket guide," 2007, http://www .whiar.org/docs/ARIA_PG_08_View_WM.pdf. 
[10] S. Bavbek, H. Kumbasar, H. Tugcu, and Z. Misirligil, "Psychological status of patients with seasonal and perennial allergic rhinitis," Journal of Investigational Allergology and Clinical Immunology, vol. 12, no. 3, pp. 204-210, 2002.

[11] Y. Graif, A. Goldberg, R. Tamir, D. Vigiser, and S. Melamed, "Skin test results and self-reported symptom severity in allergic rhinitis: the role of psychological factors," Clinical and Experimental Allergy, vol. 36, no. 12, pp. 1532-1537, 2006.

[12] R. D. Goodwin, M. Castro, and M. Kovacs, "Major depression and allergy: does neuroticism explain the relationship?" Psychosomatic Medicine, vol. 68, no. 1, pp. 94-98, 2006.

[13] R. C. Knibb and S. L. Horton, "Can illness perceptions and coping predict psychological distress amongst allergy sufferers?" British Journal of Health Psychology, vol. 13, no. 1, pp. 103-119, 2008.

[14] M. Osman, A. L. Hansell, C. R. Simpson, J. Hollowell, and P. J. Helms, "Gender-specific presentations for asthma, allergic rhinitis and eczema in primary care," Primary Care Respiratory Journal, vol. 16, no. 1, pp. 28-35, 2007.

[15] B. Marklund, S. Ahlstedt, and G. Nordström, "Healthrelated quality of life among adolescents with allergy-like conditions-with emphasis on food hypersensitivity," Health and Quality of Life Outcomes, vol. 2, article 65, 2004.

[16] R. A. Nathan, "The pathophysiology, clinical impact, and management of nasal congestion in allergic rhinitis," Clinical Therapeutics, vol. 30, no. 4, pp. 573-586, 2008.

[17] A. Shedden, "Impact of nasal congestion on quality of life and work productivity in allergic rhinitis: findings from a large online survey," Treatments in Respiratory Medicine, vol. 4, no. 6, pp. 439-446, 2005.

[18] V. Bauchau and S. R. Durham, "Prevalence and rate of diagnosis of allergic rhinitis in Europe," European Respiratory Journal, vol. 24, no. 5, pp. 758-764, 2004.

[19] J. O'Connor, C. Seeto, B. Saini, et al., "Healthcare professional versus patient goal setting in intermittent allergic rhinitis," Patient Education and Counseling, vol. 70, no. 1, pp. 111-117, 2008. 


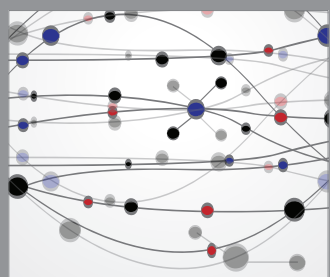

The Scientific World Journal
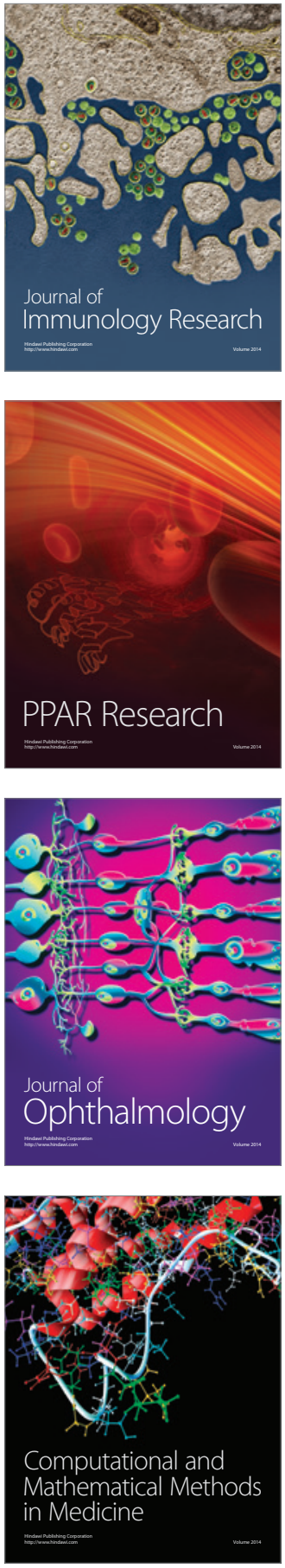

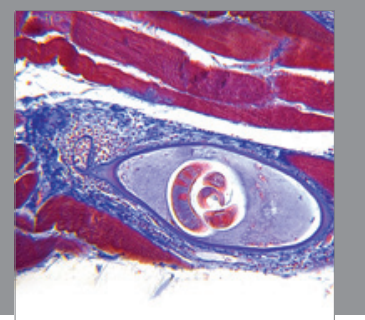

Gastroenterology

Research and Practice
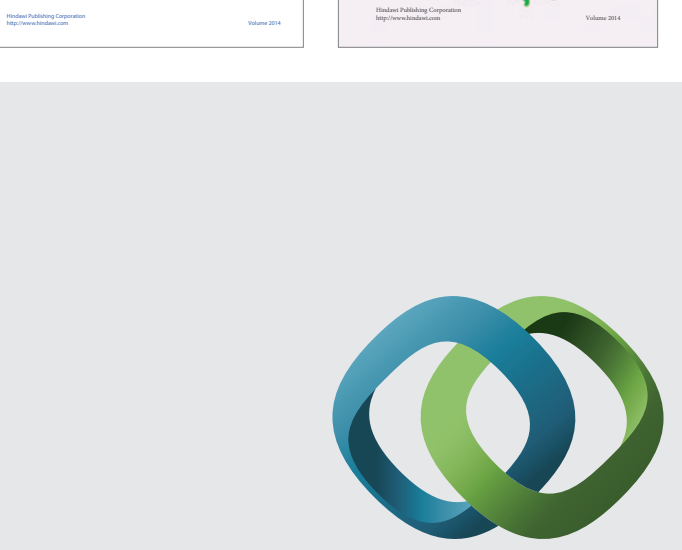

\section{Hindawi}

Submit your manuscripts at

http://www.hindawi.com
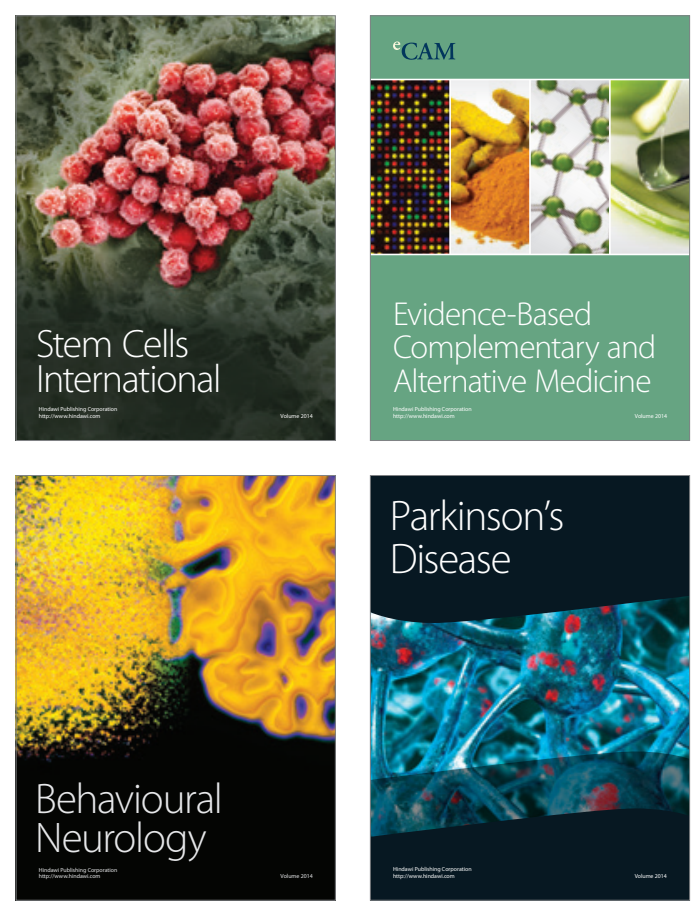

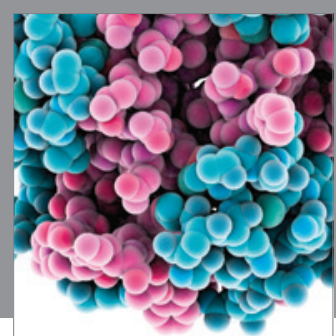

Journal of
Diabetes Research

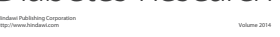

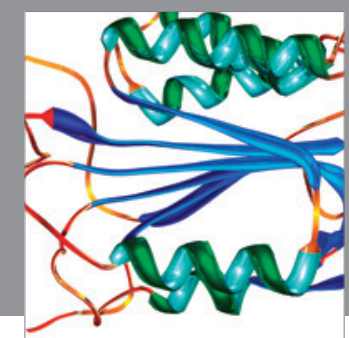

Disease Markers
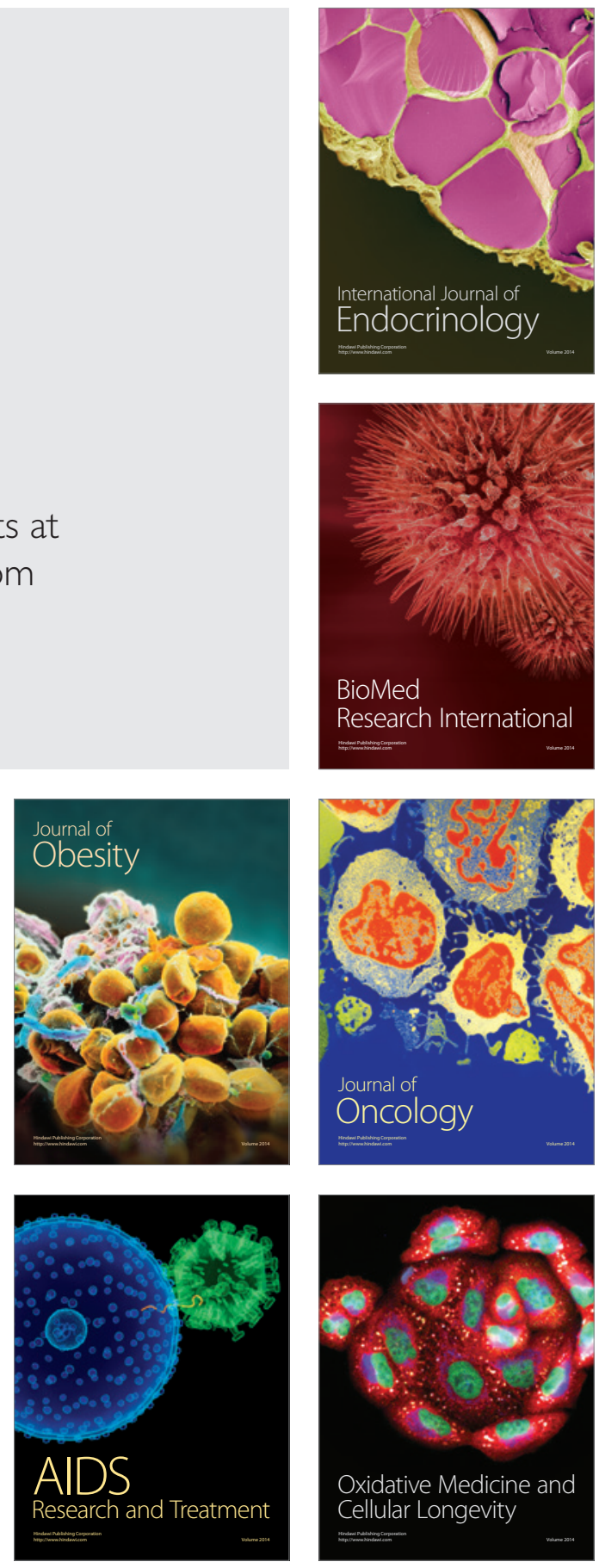